\title{
Relationship with Parents, Emotion Regulation, and Callous-Unemotional Traits in Adolescents' Internet Addiction
}

\author{
Carmen Trumello $\left(D,{ }^{1}\right.$ Alessandra Babore, ${ }^{1}$ Carla Candelori, ${ }^{1}$ \\ Mara Morelli, ${ }^{2}$ and Dora Bianchi ${ }^{3}$ \\ ${ }^{1}$ Department of Psychological, Humanistic and Territorial Sciences, University “G. d’Annunzio", Chieti, Italy \\ ${ }^{2}$ Department of Human and Social Sciences, Université de la Vallée d'Aoste, Italy \\ ${ }^{3}$ Department of Developmental and Social Psychology, Sapienza University of Rome, Italy
}

Correspondence should be addressed to Carmen Trumello; c.trumello@unich.it

Received 15 December 2017; Revised 13 March 2018; Accepted 12 April 2018; Published 23 May 2018

Academic Editor: Carlos A. Almenara

Copyright (C) 2018 Carmen Trumello et al. This is an open access article distributed under the Creative Commons Attribution License, which permits unrestricted use, distribution, and reproduction in any medium, provided the original work is properly cited.

\begin{abstract}
The aim of this study was to investigate the associations of relationship with parents, emotion regulation, and callous-unemotional traits with Internet addiction in a community sample of adolescents. Self-report measures of relationship with parents (both mothers and fathers), emotion regulation (in its two dimensions: cognitive reappraisal and expressive suppression), callousunemotional traits (in its three dimensions: callousness, uncaring, and unemotional), and Internet addiction were completed by 743 adolescents aged 10 to 21 years. Results showed that a low perceived maternal availability, high cognitive reappraisal, and high callousness appeared to be predictors of Internet addiction. The implications of these findings are then discussed.
\end{abstract}

\section{Introduction}

Adolescence is known to be a period of major transformations in psychological and bodily aspects, openness to new experiences, and construction of a personal identity. In this process, an important role is played by new technologies, which attract much interest among young people, as a means to promote social relationships [1] and to freely explore a "wider world".

The Internet, accessible through a large number of devices, is highly integrated in the daily experiences of adolescents $[2,3]$. Recent studies found associations between new technology use (e.g., the Internet and video games) and typical adolescent needs, such as self-affirmation, belonging, and identity exploration $[4,5]$. Despite the normative nature of and subsequent convenience provided by new technology use among adolescents, an excessive use can potentially become problematic, as it may result in serious psychosocial dysfunction, evident in arguments with and lying to relatives and friends, poor achievement, and social withdrawal $[6,7]$.
However, previous results on the association between time spent online and problematic Internet use, as synthesised in a meta-analysis by Tokunaga and Rains [8], are not so obvious as it might be supposed. In fact, some authors (e.g., [9]) underlined a positive relation between time using Internet and Internet addiction, while others (e.g., [10]) found only a weak association.

More generally, many authors have recently underlined the risk factors related to a problematic Internet use among adolescents [11-14], including the possibility of Internet addiction [15]. Despite the controversies about a consistent nomenclature (e.g., Internet dependency, problematic use of the Internet) and the criteria for Internet addiction, the consensus among researchers is that adolescents may especially be at risk for the detrimental use of the Internet [16] because of their limited capacity of self-regulation and their vulnerability to peer pressure [17].

The problematic use of the Internet is characterised by some aspects that are also present in other addictive disorders [18]. Block [19] particularly identified the four following 
components: excessive use (with a loss of one's sense of time), withdrawal (including a sense of anger and/or depression and anxiety when the Internet is not available), obsession (constant need for better digital technologies or more hours of use), and negative consequences (arguments, lying, poor achievement, and social isolation).

Consistent with this view, we use the term "Internet addiction" in this study to refer to the damaging use of the Internet as linked to dysfunctional effects on the emotive and social areas of adolescents' life [20]. As Tokunaga [21] suggested in a recent meta-analysis, clinicians described this addiction as a loss of conscious self-control over Internet use. Many studies underlined the loss of self-control in populations susceptible to addiction (e.g., anxious/depressed people), in regular Internet users [22] and, in an increasingly worrying way, among adolescents $[15,23,24]$.

Research has demonstrated that difficulties in emotion regulation play an important role in situations of addictive behaviours $[25,26]$, problematic use of the Internet [27, 28], and pathological use of social networking sites [29]. According to Gross et al. [30], emotion regulation is a subtype of affect regulation (the other subtypes are coping and mood regulation) that refers to attempts to influence emotional experience, whether consciously or unconsciously, and may involve the up- or downregulation (i.e., increase or decrease) of various aspects of positive or negative emotions [31]. Two commonly used strategies for downregulating emotion are cognitive reappraisal and expressive suppression. Reappraisal involves changes in the way a situation is construed to decrease its emotional impact in negative emotion contexts. By contrast, suppression inhibits the external signs of inner feelings and the emotion-expressive behaviour [32].

Compared with research on adults, fewer studies have explored emotional regulation as linked to Internet addiction in adolescents, focusing mainly on the connection between emotional regulation and a problematic Internet use.

For example, in a study that involved 525 high school students, Yu et al. [33] observed that adolescents' difficulties in emotion regulation were significantly associated with problematic Internet use. Another recent research [34], conducted on a sample of 380 adolescent students from a secondary school in Italy, confirmed that emotion regulation was negatively correlated with a dysfunctional use of the Internet. However, there is a lack of knowledge regarding which emotion regulation strategy plays a major role in these dysfunctional behaviours.

Another important aspect studied in empirical research on adolescents' Internet addiction is the possible influence of relationship with parents. In the literature, the consensus is that adolescents' relationship with their parents may deeply influence their psychosocial well-being [35, 36] and life satisfaction and that different parenting styles are linked to different psychosocial profiles, particularly in the selfconcept domain [37].

In several studies, Yu and Gamble [38-40] stated that adolescents who perceived their parents as warmer and nonrejecting were less likely to exhibit negative or problematic psychosocial behaviours. On the contrary, adolescents whose parents were perceived to be more rejecting and unsupportive demonstrated a greater risk for problematic behaviours and psychosocial outcomes, such as Internet addiction [41].

Several studies have investigated the correlation between the quality of parent-adolescent relationship and problematic Internet use. For example, positive parental relationships were found to be negatively correlated with Internet addiction [42], whereas conflictual relationships were positively associated with Internet addiction [43]. In the presence of Internet addiction, adolescents described their parents as lacking in warmth, more intrusive, rejecting, and punitive [44].

However, while numerous studies have examined the connection between Internet addiction in adolescence and quality of parental relationship, research with a specific focus on adolescents' Internet addiction and parents' perceived emotional availability [45] is lacking.

Emotional availability refers to a set of aspects (e.g., support, sensitivity, and responsiveness) that relate to the emotional bond with parents [46]. According to Lum and Phares [45], this construct is consistent with theoretical and empirical evidence that emotionally available parents are related to a child's greater sense of security, promoting the development of personal and interpersonal competencies.

All these aspects suggest the importance of exploring different factors, individual and interpersonal, which may increase or decrease the risk of adolescents' problematic Internet use.

In this frame, we examined an additional factor, the role of callous-unemotional (CU) traits, which, in recent years, have been the focus of much attention in studies on behavioural problems $[47,48]$. CU traits can be defined as a set of characteristics including lack of empathy, remorse and guilt, and lack of concern about the negative impacts of one's own actions [49]. The growing interest on CU trait assessment resulted in the development of the Inventory of Callous-Unemotional Traits (ICU) by Frick and colleagues $[50,51]$. The three following dimensions are analysed with the use of this widely used self-report tool: callousness, which refers to the lack of empathy, guilt, and remorse for misdeeds; uncaring, which encompasses lack of care for one's own actions and for other people's feelings; and unemotional, which refers to shallow or deficient affects $[52,53]$.

Although CU traits have been traditionally considered the core affective dimension of psychopathy, several studies found their association with poor peer relationships, low prosociality, and psychosocial maladjustment in community adolescents [47, 53, 54]. Previous research also highlighted the relation of CU traits with aggressiveness, drug consumption, and multiple psychosocial impairments in children and adolescents $[48,55]$. Commenting on the findings of studies on this topic, Viding and McCrory [54] suggested that CU traits may, overall, be considered a risk factor for poorer social functioning.

So far, despite previous research showing the association of CU traits with psychosocial maladjustment, no published study has focused on the relationship between CU traits and Internet addiction.

Starting from these premises, the current research pursued different goals. First, we aimed to analyse the associations between the use of new technologies and the Internet 
addiction. Given the results of existing research, we expect a positive correlation between these two variables.

Second, we aimed to explore if and to what extent three specific areas, namely, perceptions of parenting relationship (in terms of emotional availability), emotion regulation strategies (cognitive reappraisal and expressive suppression), and CU traits (callousness, unemotional, and uncaring), may be related to Internet addiction. Specifically, we hypothesised that perceptions of a low parenting relationship and high levels of CU traits could be possible predictors of Internet addiction.

With regard to emotion regulation, even if other studies have explored this issue, the particular emotion regulation strategy that may be involved in Internet addiction during adolescence is unclear. Thus, in this study, we aimed not only to explore the relation between emotional regulation and Internet addiction in this particular phase of development but also to verify whether a particular emotion regulation strategy (cognitive reappraisal and/or expressive suppression) may be predictive of Internet addiction. Given the lack of specific research exploring individual emotion regulation strategies, we do not advance any hypothesis on whether and what particular emotion regulation strategy may have a predictive power for Internet addiction.

\section{Materials and Methods}

2.1. Participants. The study was conducted on 743 Italian participants aged 10 to 21 years $\left(\mathrm{M}_{\mathrm{age}}=15.64 ; \mathrm{SD}_{\text {age }}=2.08\right.$; $57.6 \%$ females). They were recruited in public schools in urban and suburban areas of Chieti and Rome. Paper-andpencil questionnaires were administered, and all participants gave their informed consent in accordance with the Declaration of Helsinki. For underage participants, written informed consent was also obtained from their parents and from school authorities. The Ethics Committee of the Department of Psychological Sciences of the University approved this study.

\subsection{Measures}

Sociodemographic Data. The participants reported their age, gender, and information regarding their family.

New Technology Use. Nine items selected from the Questionnaire about New Digital Technologies (QNDT) were administered to evaluate some behaviours related to Internet and video game use. Two items measured the amount of time spent online daily and the amount of time spent on video games daily on a four-point Likert scale ranging from 1 (less than 1 hour) to 4 (more than 3 hours), and five items assessed the role of parents in Internet use on a four-point Likert scale ranging from 1 (never) to 4 (very often). Specifically, the items investigated playing video games with the mother, playing video games with the father, using the Internet with the mother, using the Internet with the father, and quarrels with parents on the amount of time spent on the Internet or on video games. Finally, two dichotomous items evaluated parental restriction and making friends online $(0=n o$ and $1=$ yes $)$.
Perceived Emotional Availability of Parents. To evaluate the participants' perception of maternal and paternal emotional availability, we administered the two versions of the Lum Emotional Availability of Parents (LEAP) questionnaire [45, 56, 57]. Each version (LEAP-mother and LEAP-father) comprised the same 15 items rated on a six-point Likert scale ranging from 1 (never) to 6 (always). A higher score reflects a higher level of perceived emotional availability. Both LEAPmother and LEAP-father reached good reliability, with a Cronbach's alpha of .94 and .96, respectively.

Emotion Regulation. The Emotion Regulation Questionnaire (ERQ) $[58,59]$ was administered to assess expressive suppression and cognitive reappraisal, two specific emotion regulation strategies which are typically used to manage positive and negative emotions in daily life. The expressive suppression scale is composed of four items evaluating the inhibition of emotion-expressive behaviour. The cognitive reappraisal scale is composed of six items evaluating the cognitive ability of modifying the meaning and the emotional impact of a situation. All items were rated on a seven-point Likert scale ranging from 1 (strongly disagree) to 7 (strongly agree). The expressive suppression scale and the cognitive reappraisal scale obtained a Cronbach's alpha of .60 and .79, respectively.

Callous-Unemotional Traits. The Inventory of Callous-Unemotional Traits (ICU) $[50,52]$ is a self-report questionnaire that evaluates callous-unemotional traits, which were theorised by Frick et al. [60]. These traits are the affective dimension of psychopathy [61] and refer to the lack of empathy, guilt, and any emotional expression. The factor structure of the scale showed the presence of three subscales: callousness (nine items), unemotional (five items), and uncaring (eight items).

"Callousness" assessed the lack of empathy and remorse (Cronbach's alpha of .68), "unemotional" assessed the lack of emotional expression (Cronbach's alpha of .59), and "uncaring" assessed the insensibility towards others' emotions and task performance (Cronbach's alpha of .70). All items were rated on a four-point Likert scale ranging from 0 (not at all true) to 3 (definitely true).

Internet Addiction. Internet addiction was evaluated with the 10-item Internet addiction subscale added to the Shorter Promis Questionnaire (SPQ) [62] in the SPQ Italian validation [63]. This scale measured several indexes of Internet addiction, such as difficulty in stopping Internet use, concerns of others about Internet use, and the feeling of safety and emotional relief provided by Internet use. In this study, we used only nine items; we removed the item "I connect to the Internet several times during the day" because more than $75 \%$ of the participants answered above 3 on a six-point Likert scale ranging from 1 (not at all true) to 6 (definitely true). This psychometric problem could be due to the current lack of discriminant validity of this item. Nowadays, people are continuously connected to the Internet through their smartphone. Thus, the final scale, composed of nine items, reached a good reliability, with a Cronbach's alpha of .74. 
2.3. Data Analysis. For descriptive purposes, we computed the correlations among the nine variables of the QNDT and Internet addiction to explore how the use of the Internet and video games and the role of parents are related to Internet addiction among young people. Then, the correlations among perceived maternal and paternal availability (LEAPmother and LEAP-father), the two ERQ dimensions (cognitive reappraisal and expressive suppression), the three ICU dimensions (callousness, unemotional, and uncaring), and Internet addiction were computed. Afterwards, a multiple linear regression analysis was run to investigate whether perceived maternal and paternal availability, emotion regulation strategies, and callous-unemotional traits could lead to Internet addiction. In our study, we considered all investigated variables (perceived maternal and paternal availability, two emotion regulation strategies, and three callous-unemotional traits) as predictors, according to J. Cohen and P. Cohen [64] and Cohen et al. [65]. In fact, according to them, in regression analysis, the criteria (dependent variable) are regressed on the predictors (independent variables), and these terms avoid the possible interpretation of casual effects among variables.

\section{Results}

3.1. Correlations between Internet Addiction and New Technology Use. Internet addiction was negatively and weakly related to age. Conversely, Internet addiction was positively and modestly related to the amount of time spent online daily, the amount of time spent on video games daily, making friends online, and quarrels with parents on the amount of time spent on the Internet or on video games. On the contrary, Internet addiction was not related to gender, playing video games with the mother, playing video games with the father, using the Internet with the mother, using the Internet with the father, and parental restriction. The correlations and descriptive statistics are reported in Table 1.

3.2. Correlations among Perceived Parental Availability, Emotion Regulation Strategies, Callous-Unemotional Traits, and Internet Addiction. Internet addiction was negatively and weakly related to perceived maternal availability. Conversely, Internet addiction was positively and weakly related to cognitive reappraisal and expressive suppression. Moreover, Internet addiction was positively and modestly related to callousness. The correlations and descriptive statistics are reported in Table 2 .

3.3. Multiple Linear Regression Analysis. A multiple linear regression analysis was run to determine whether perceived maternal and paternal availability, emotion regulation strategies (i.e., cognitive reappraisal and expressive suppression), and callous-unemotional traits (i.e., callousness, unemotional, and uncaring) could lead to Internet addiction. Perceived maternal availability, beta $=-.10, p=.02$; cognitive reappraisal, beta $=.08, p=.03$; and callousness, beta $=.24$, $p<.001$ turned out to be significant predictors of Internet addiction, accounting for $8.1 \%$ of the variance, $R=.28$, $p<.001$. Thus, low maternal availability, high cognitive reappraisal, and high callousness appeared to be predictors of Internet addiction. The full statistics of the model are reported in Table 3.

\section{Discussion}

This study was developed to explore the association of Internet addiction with the use of new technologies, relationship with parents (both mothers and fathers), emotion regulation (in its two dimensions: cognitive reappraisal and expressive suppression), and callous-unemotional traits (in its three dimensions: callousness, uncaring, and unemotional) among Italian adolescents.

For the first aim, our data showed a positive but modest relationship of time spent on video games and online with Internet addiction. Existing research on this topic produced mixed results $[9,10,66]$. In his analysis Block [19] suggested that an excessive time spent on the Internet characterises Internet addiction, while following Gamito et al's suggestion [67], a simple frequency of use could not be an indicator of addiction or risk of addiction, since specific uses of the Internet may be addictive. Hence, it might not be appropriate to refer only to the amount of time spent online as the criterion for identifying Internet addiction, because adolescents may use the Internet for different purposes [10], spending a lot of time online, without missing their ability to control this activity.

Therefore, in order to distinguish between adaptive and maladaptive use of the Internet, other processes should be explored, such as emotional and self-regulatory ones.

With regard to emotion regulation, we found a predictive association between cognitive reappraisal and Internet addiction. According to Gross' process model of emotion regulation [68] and his studies on the affective, cognitive, and social consequences of emotion regulation strategies [32], reappraisal is associated with a greater positive emotion experience and expression and a lesser negative emotion experience than suppression is. Therefore, as cognitive reappraisal involves reinterpreting negative emotional stimuli in a nonemotional manner [68], Internet overuse seems to be an attempt of adolescents to avoid difficult emotions through instant emotional gratification or avoidance, distraction, and disengagement $[26,69]$. In fact, as Spada et al. [70] stated, an excessive use of the Internet may be a form of maladaptive self-regulatory strategy because it may be useful for distracting adolescents from negative affective states. Besides, contrary to suppression, cognitive reappraisal is evoked early in the emotion generative process, and it is not necessarily a continual self-regulatory effort during an emotional event [32]. As adolescents experience continuous emotional changes and the need for instant emotional gratification, reappraisal can be hypothesised as the most immediate strategy that can be used towards negative emotions.

Our results provide an important contribution to the literature on Internet addiction in adolescents because they showed the predictive power of a specific emotion regulation strategy (cognitive reappraisal) in Internet addiction. However, our findings must be considered with caution, and they require further study. 


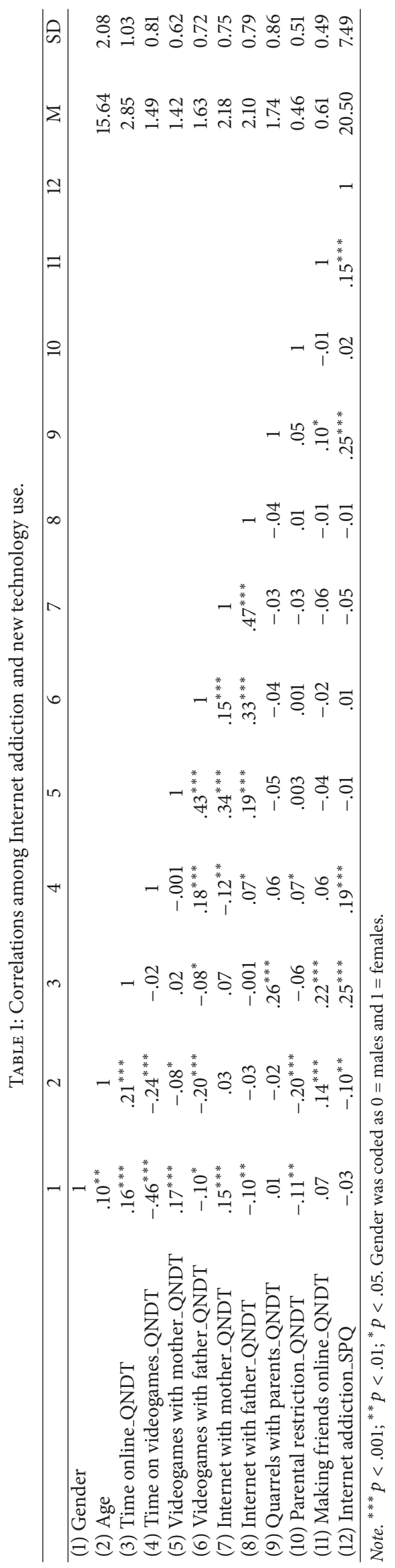




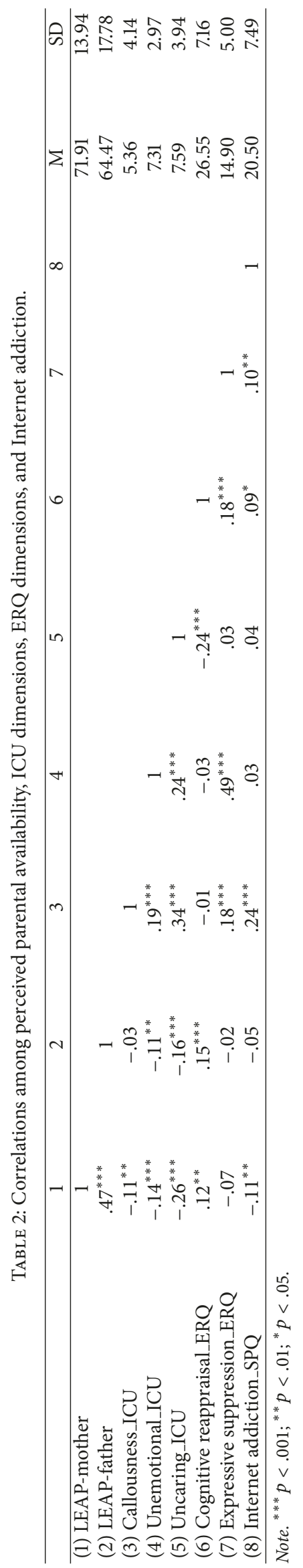


TABLE 3: Multiple linear regression analysis $(N=743)$.

\begin{tabular}{lc}
\hline & Internet addiction \\
Predictor & Beta \\
\hline LEAP-mother & $-.10^{*}$ \\
LEAP-father & -.02 \\
Callousness & $.24^{* *}$ \\
Unemotional & -.05 \\
Uncaring & -.04 \\
Cognitive reappraisal & $.08^{*}$ \\
Expressive suppression & .07 \\
Total $R^{2}$ & \\
\hline
\end{tabular}

Note. ${ }^{*} p<.05 ;{ }^{* *} p<.001$. The interaction effects between all investigated variables (perceived maternal and paternal availability, the two emotion regulation strategies, and the three callous-unemotional traits) and gender, and between all investigated variables (perceived maternal and paternal availability, the two emotion regulation strategies, and the three callousunemotional traits) and age were tested to examine the possible moderating effects of gender and age. An initial hierarchical regression analysis was run to verify the interaction effects between gender and all investigated variables on Internet addiction. The interaction terms were entered in the second step, but no significant interaction effects were found. Another hierarchical regression analysis was run to verify the interaction effects between age and all investigated variables on Internet addiction. The interaction terms were also entered in the second step, but no significant interaction effects were found.

Indeed, adolescence is a period of emotive and psychosocial changes, characterised by a hyperactivated emotional-behavioural functioning with a major tendency towards action [71], especially if one lacks self-regulatory strategies [2]. In this phase, because of the lesser emotion self-control capacity, adolescents may be more vulnerable to and at risk for developing addictive behaviours, such as Internet addiction, and other problematic behaviours [72-74].

According to our findings, the callousness dimension was the strongest predictor of Internet addiction among the variables we considered. The two other dimensions encompassed in the ICU, unemotional and uncaring, were not significantly related to Internet addiction. This result is quite new because, to our knowledge, this is the first study to analyse the role of $\mathrm{CU}$ traits in this kind of addiction. Among other forms of addictive behaviours, $\mathrm{CU}$ traits were found in a prospective study by Wymbs et al. [75] to predict substance use among early adolescent boys; more recently, Romero and Alonso [48] found that, compared with the uncaring and unemotional dimensions, callousness was the strongest predictor of alcohol and cannabis consumption among a sample of Spanish adolescents. The callousness dimension was also associated with gambling disorder in a sample of nonreferred Italian gamblers [76]. These last two studies emphasised the importance of callousness in the comprehension of addictive disorders, a result that resembles that of the current study. More specifically, Internet addiction is often characterised by social isolation and withdrawal, a feature that might be consistent with our findings of a positive correlation with callousness. In fact, callousness may be considered as the $\mathrm{CU}$ trait dimension most closely related to lack of empathy [48].

Even if this did not fall within the objectives of the study, our data showed a highly positive association between the unemotional dimension of $\mathrm{CU}$ traits and the expressive suppression strategy of emotional regulation. This finding highlights an overlap between these two constructs, which is not surprising because adolescents with $\mathrm{CU}$ traits are classically defined as lacking emotional expression [61] and having limited emotional depth [77] and deficits in emotional processing [78]. Furthermore, we analysed the connection between Internet addiction and the emotional quality of relationship with parents, both mothers and fathers. Our results showed that maternal emotional availability, but not paternal emotional availability, predicted Internet addiction. More specifically, lower levels of emotional quality in maternal relationship were associated with higher levels of Internet addiction. This result is quite new, as previous research did not specifically consider the construct of parental emotional availability and instead focused on the more general parent-child relationship quality. A recent review by Schneider et al. [79] analysed 11 previous studies showing that a poorer quality of parent-child bond correlated with an increased severity in problematic Internet gaming. Moreover, previous studies focusing on adolescents' overall psychological adjustment highlighted that maternal parenting played a more relevant role than paternal parenting did [80, 81]. Overall, an inadequate maternal emotional availability and unemotional exchanges between mother and child may be argued to lead to negative relationships with others, selfperceived loneliness, and sadness [82], which, in turn, may predict the development of Internet addiction [2].

Some limitations of this study have to be considered. First, the exclusive use of self-report tools and the absence of other informants (e.g., parents and/or teachers) do not address the issue of shared method variance bias. Moreover, because of the cross-sectional nature of the research, no causal relationships among the considered variables may be inferred. Lastly, as our data refer to an Italian sample of adolescents, the generalisation of the findings to other countries cannot be done.

Nevertheless, the present research made a relevant contribution to knowledge on the significant factors associated with Internet addiction. In particular, our study was the first to analyse the role played by parental emotional availability, specific emotion regulation strategies, and callous-unemotional traits in Internet addiction.

\section{Conclusion}

Nowadays, Internet addiction is increasingly studied because of the negative effects this addiction may have on adolescents; it results in a higher risk for aggressive behaviours [83], poorer school performance [84], low quality of interpersonal relationships $[85,86]$, and an increase in depressive symptoms $[15,87]$. Furthermore, adolescents with Internet addiction are more exposed to other important risks linked to the world of the Web, such as cyber bullying, sexual solicitation, and identity theft. 
The early recognition of Internet addiction among adolescents and the possibility of preventing this addictive behaviour are crucial. As Di Nicola et al. [88] underlined in a recent study, the last European School Survey Project on Alcohol and Other Drugs [89] report of 2016 stated that "since the Internet has become an integral part of life and is used on a daily basis, the development of patterns of addictive use among children and adolescents needs to be closely monitored and investigated in further studies" and that "measures to prevent adolescents from developing problems associated with gambling, such as debts, psychological deficits and social disadvantages, are of high priority".

\section{Conflicts of Interest}

The authors declare that there are no conflicts of interest regarding the publication of this article.

\section{References}

[1] R. Baiocco, F. Laghi, M. Carotenuto, and C. Del Miglio, "Amicizia on-line: disimpegno o stimolazione," Psicologia Clinica dello Sviluppo, vol. 2, pp. 336-352, 2011.

[2] L. Cerniglia, F. Zoratto, S. Cimino, G. Laviola, M. Ammaniti, and W. Adriani, "Internet Addiction in adolescence: Neurobiological, psychosocial and clinical issues," Neuroscience \& Biobehavioral Reviews, vol. 76, pp. 174-184, 2017.

[3] L. Cerniglia, "Brief considerations on internet use in adolescence," EC Psychology and Psychiatry, no. 1, pp. 10-11, 2017.

[4] S. M. Gainsbury, "Online gambling addiction: the relationship between internet gambling and disordered gambling," Current Addiction Reports, vol. 2, no. 2, pp. 185-193, 2015.

[5] E. C. Tzavela, C. Karakitsou, M. Dreier et al., "Processes discriminating adaptive and maladaptive Internet use among European adolescents highly engaged online," Journal of Adolescence, vol. 40, pp. 34-47, 2015.

[6] H.-M. Sinkkonen, H. Puhakka, and M. Meriläinen, "Internet use and addiction among Finnish Adolescents (15-19 years)," Journal of Adolescence, vol. 37, no. 2, pp. 123-131, 2014.

[7] I. Reiner, A. N. Tibubos, J. Hardt, K. W. Müller, K. Wölfling, and M. E. Beutel, "Peer attachment, specific patterns of internet use and problematic internet use in male and female adolescents," European Child and Adolescent Psychiatry, vol. 26, no. 10, pp. 1257-1268, 2017.

[8] R. S. Tokunaga and S. A. Rains, "An evaluation of two characterizations of the relationships between problematic internet use, time spent using the internet, and psychosocial problems," Human Communication Research, vol. 36, no. 4, pp. 512-545, 2010.

[9] M. Israelashvili, T. Kim, and G. Bukobza, “Adolescents' over-use of the cyber world - Internet addiction or identity exploration?" Journal of Adolescence, vol. 35, no. 2, pp. 417-424, 2012.

[10] M. K. Chang and S. P. M. Law, "Factor structure for Young's Internet addiction test: a confirmatory study," Computers in Human Behavior, vol. 24, no. 6, pp. 2597-2619, 2008.

[11] R. Baiocco, M. Manca, A. Couyoumdjian, R. Cerruti, and C. Del Miglio, "Uso e abuso di internet in adolescenza: quale relazione con i disturbi psicosomatici?” Psicotech, vol. 2, pp. 47-60, 2005.

[12] D. J. Kuss, A. J. Van Rooij, G. W. Shorter, M. D. Griffiths, and D. Van De Mheen, "Internet addiction in adolescents: Prevalence and risk factors," Computers in Human Behavior, vol. 29, no. 5, pp. 1987-1996, 2013.

[13] L. Milani, G. La Torre, M. Fiore et al., "Internet gaming addiction in adolescence: risk factors and maladjustment correlates," International Journal of Mental Health and Addiction, 2017.

[14] L. Sideli, C. La Cascia, C. Sartorio et al., "Internet out of control: The role of self-esteem and personality traits in pathological internet use," Clinical Neuropsychiatry, vol. 14, no. 1, pp. 88-93, 2017.

[15] S. K. Park, J. Y. Kim, and C. B. Cho, "Prevalence of internet addiction and correlations with family factors among South Korean adolescents," Family Therapy, vol. 36, no. 3, pp. 163-177, 2009.

[16] M. D. Griffiths, "Social networking addiction: emerging themes and issues," Journal of Addiction Research \& Therapy, vol. 4, no. 5, article el18, 2013.

[17] G. S. O'Keeffe and K. Clarke-Pearson, “The Impact of Social Media on Children, Adolescents, and Families," Pediatrics, vol. 127, no. 4, pp. 800-804, 2011.

[18] J. Billieux, P. Maurage, O. Lopez-Fernandez, D. J. Kuss, and M. D. Griffiths, "Can disordered mobile phone use be considered a behavioral addiction? An update on current evidence and a comprehensive model for future research," Current Addiction Reports, vol. 2, no. 2, pp. 156-162, 2015.

[19] J. J. Block, "Issues for DSM-V: Internet addiction," The American Journal of Psychiatry, vol. 165, no. 3, pp. 306-307, 2008.

[20] M. Mihajlov and L. Vejmelka, "Internet addiction: A review of the first twenty years," Psychiatria Danubina, vol. 29, no. 3, pp. 260-272, 2017.

[21] R. S. Tokunaga, "A meta-analysis of the relationships between psychosocial problems and internet habits: Synthesizing internet addiction, problematic internet use, and deficient selfregulation research," Communication Monographs, vol. 84, no. 4, pp. 423-446, 2017.

[22] R. LaRose, C. A. Lin, and M. S. Eastin, "Unregulated Internet usage: Addiction, habit, or deficient self-regulation?" Media Psychology, vol. 5, no. 3, pp. 225-253, 2003.

[23] C. Flisher, "Getting plugged in: An overview of Internet addiction," Journal of Paediatrics and Child Health, vol. 46, no. 10, pp. 557-559, 2010.

[24] M. M. Spada, "An overview of problematic Internet use," Addictive Behaviors, vol. 39, no. 1, pp. 3-6, 2014.

[25] H. C. Fox, S. R. Axelrod, P. Paliwal, J. Sleeper, and R. Sinha, "Difficulties in emotion regulation and impulse control during cocaine abstinence," Drug and Alcohol Dependence, vol. 89, no. 2-3, pp. 298-301, 2007.

[26] B. Kun and Z. Demetrovics, "Emotional intelligence and addictions: a systematic review," Substance Use \& misuse, vol. 45, no. 7-8, pp. 1131-1160, 2010.

[27] S. E. Caplan, "Theory and measurement of generalized problematic Internet use: A two-step approach," Computers in Human Behavior, vol. 26, no. 5, pp. 1089-1097, 2010.

[28] S. Casale, S. E. Caplan, and G. Fioravanti, "Positive metacognitions about Internet use: The mediating role in the relationship between emotional dysregulation and problematic use," Addictive Behaviors, vol. 59, pp. 84-88, 2016.

[29] J. M. Hormes, B. Kearns, and C. A. Timko, "Craving Facebook? Behavioral addiction to online social networking and its association with emotion regulation deficits," Addiction, vol. 109, no. 12, pp. 2079-2088, 2014. 
[30] J. J. Gross, J. M. Richards, and O. P. John, "Emotion regulation in everyday life," in Emotion Regulation in Families: Pathways to Dysfunction and Health, D. K. Snyder, J. A. Simpson, and J. N. Hughes, Eds., pp. 13-35, American Psychological Association, Washington, DC, USA, 2006.

[31] W. G. Parrott, "Beyond hedonism: motives for inhibiting good moods and for maintaining bad moods," in Handbook of Mental Control, D. M. Wegner and J. W. Pennebaker, Eds., pp. 278-308, Prentice Hall, Englewood Cliffs, NJ, USA, 1993.

[32] J. J. Gross, "Emotion regulation: affective, cognitive, and social consequences," Psychophysiology, vol. 39, no. 3, pp. 281-291, 2002.

[33] J. J. Yu, H. Kim, and I. Hay, "Understanding adolescents' problematic Internet use from a social/cognitive and addiction research framework," Computers in Human Behavior, vol. 29, no. 6, pp. 2682-2689, 2013.

[34] M. M. Spada and C. Marino, "Metacognitions and emotion regulation as predictors of problematic internet use in adolescents," Clinical Neuropsychiatry, vol. 14, no. 1, pp. 59-63, 2017.

[35] A. Babore, C. Trumello, C. Candelori, M. Paciello, and L. Cerniglia, "Depressive symptoms, self-esteem and perceived parent-child relationship in early adolescence," Frontiers in Psychology, vol. 7, article 982, 2016.

[36] A. Babore, L. Carlucci, F. Cataldi, V. Phares, and C. Trumello, "Aggressive behaviour in adolescence: Links with self-esteem and parental emotional availability," Social Development, vol. 26, no. 4, pp. 740-752, 2017.

[37] I. Hay and A. Ashman, "Self-concept," in Encyclopedia of Adolescence, R. J. Levesque, Ed., pp. 2516-2536, Springer, New York, NY, USA, 2012.

[38] J. J. Yu and W. C. Gamble, "Familial correlates of overt and relational aggression between young adolescent siblings," Journal of Youth and Adolescence, vol. 37, no. 6, pp. 655-673, 2008.

[39] J. J. Yu and W. C. Gamble, "Adolescent relations with their mothers, siblings, and peers: An exploration of the roles of maternal and adolescent self-criticism," Journal of Clinical Child \& Adolescent Psychology, vol. 38, no. 5, pp. 672-683, 2009.

[40] J. J. Yu and W. C. Gamble, "Direct and moderating effects of social affordances on school involvement and delinquency among young adolescents," Journal of Research on Adolescence, vol. 20, no. 4, pp. 811-824, 2010.

[41] R. A. Davis, "A cognitive-behavioral model of pathological Internet use," Computers in Human Behavior, vol. 17, no. 2, pp. 187-195, 2001.

[42] C.-Y. Liu and F.-Y. Kuo, "A study of Internet addiction through the lens of the interpersonal theory," Cyberpsychology, Behavior, and Social Networking, vol. 10, no. 6, pp. 799-804, 2007.

[43] J. Y. Yen, C. F. Yen, C. C. Chen, S. H. Chen, and C. H. Ko, "Family factors of internet addiction and substance use experience in Taiwanese adolescents," CyberPsychology \& Behavior, vol. 10, no. 3, pp. 323-331, 2007.

[44] H. Xiuqin, Z. Huimin, L. Mengchen, W. Jinan, Z. Ying, and T. Ran, "Mental health, personality, and parental rearing styles of adolescents with internet addiction disorder," Cyberpsychology, Behavior, and Social Networking, vol. 13, no. 4, pp. 401-406, 2010.

[45] J. J. Lum and V. Phares, "Assessing the emotional availability of parents," Journal of Psychopathology and Behavioral Assessment, vol. 27, no. 3, pp. 211-226, 2005.

[46] Z. Biringen, "Emotional availability: Conceptualization and research findings," American Journal of Orthopsychiatry, vol. 70, no. 1, pp. 104-114, 2000.
[47] T. D. Wall, P. J. Frick, K. A. Fanti, E. R. Kimonis, and A. Lordos, "Factors differentiating callous-unemotional children with and without conduct problems," Journal of Child Psychology and Psychiatry and Allied Disciplines, vol. 57, no. 8, pp. 976-983, 2016.

[48] E. Romero and C. Alonso, "Callous-unemotional traits and the five factor model in adolescents," Personality and Individual Differences, vol. 106, pp. 268-274, 2017.

[49] J. V. Ray, P. J. Frick, L. C. Thornton, T. D. Wall Myers, L. Steinberg, and E. Cauffman, "Callous-unemotional traits predict self-reported offending in adolescent boys: The mediating role of delinquent peers and the moderating role of parenting practices," Developmental Psychology, vol. 53, no. 2, pp. 319-328, 2017.

[50] E. R. Kimonis, P. J. Frick, J. L. Skeem et al., "Assessing callousunemotional traits in adolescent offenders: Validation of the Inventory of Callous-Unemotional Traits," International Journal of Law and Psychiatry, vol. 31, no. 3, pp. 241-252, 2008.

[51] A. Roose, P. Bijttebier, S. Decoene, L. Claes, and P. J. Frick, "Assessing the affective features of psychopathy in adolescence: A further validation of the inventory of callous and unemotional traits," Assessment, vol. 17, no. 1, pp. 44-57, 2010.

[52] E. Ciucci, A. Baroncelli, M. Franchi, F. N. Golmaryami, and P. J. Frick, "The association between callous-unemotional traits and behavioral and academic adjustment in children: Further validation of the inventory of callous-unemotional traits," Journal of Psychopathology and Behavioral Assessment, vol. 36, no. 2, pp. 189-200, 2014.

[53] S. Oshukova, R. Kaltiala-Heino, M. Kaivosoja, and N. Lindberg, "Self-assessed limited prosocial emotions do not distinguish community youth with psychosocial problems from those without them," Nordic Journal of Psychiatry, vol. 71, no. 2, pp. 126-130, 2017.

[54] E. Viding and E. J. McCrory, "Why should we care about measuring callous-unemotional traits in children?" The British Journal of Psychiatry, vol. 200, no. 3, pp. 177-178, 2012.

[55] P. J. Frick, J. V. Ray, L. C. Thornton, and R. E. Kahn, "Annual research review: A developmental psychopathology approach to understanding callous-unemotional traits in children and adolescents with serious conduct problems," Journal of Child Psychology and Psychiatry and Allied Disciplines, vol. 55, no. 6, pp. 532-548, 2014.

[56] A. Babore, L. Picconi, C. Candelori, and C. Trumello, "The emotional relationship with parents: A validation study of the LEAP among Italian adolescents," European Journal of Developmental Psychology, vol. 11, no. 6, pp. 728-739, 2014.

[57] A. Babore, C. Candelori, and L. Picconi, "Parental emotional availability in adolescence: preliminary data from the validation of the Lum Emotional Availability of Parents (LEAP)," Psicologia Clinica dello Sviluppo, vol. 16, no. 3, pp. 639-649, 2012.

[58] J. J. Gross and O. P. John, "Individual differences in two emotion regulation processes: implications for affect, relationships, and well-being," Journal of Personality and Social Psychology, vol. 85, no. 2, pp. 348-362, 2003.

[59] S. Balzarotti, O. P. John, and J. J. Gross, "An Italian adaptation of the emotion regulation questionnaire," European Journal of Psychological Assessment, vol. 26, no. 1, pp. 61-67, 2010.

[60] P. J. Frick, E. R. Kimonis, D. M. Dandreaux, and J. M. Farell, "The 4 year stability of psychopathic traits in non-referred youth," Behavioral Sciences \& the Law, vol. 21, no. 6, pp. 713-736, 2003. 
[61] R. D. Hare and C. S. Neumann, "Psychopathy as a clinical and empirical construct," Annual Review of Clinical Psychology, vol. 4, pp. 217-246, 2008.

[62] G. Christo, S. L. Jones, S. Haylett, G. M. Stephenson, R. M. H. Lefever, and R. Lefever, "The shorter PROMIS Questionnaire: further validation of a tool for simultaneous assessment of multiple addictive behaviours," Addictive Behaviors, vol. 28, no. 2, pp. 225-248, 2003.

[63] A. Couyoumdjian, R. Baiocco, and C. Del Miglio, Adolescenti e Nuove Dipendenze, Laterza, Roma, Italy, 2006.

[64] J. Cohen and P. Cohen, Applied Multiple Regression/Correlation Analysis for the Behavioral Sciences, Erlbaum, Hillsdale, NJ, USA, 1983.

[65] J. Cohen, P. Cohen, S. G. West, and L. S. Aiken, Applied Multiple Regression/Correlation Analysis for the Behavioral Sciences, Routledge, Hillsdale, NJ, USA, 2013.

[66] Y. Khazaal, J. Billieux, G. Thorens et al., "French validation of the internet addiction test," CyberPsychology \& Behavior, vol. 11, no. 6, pp. 703-706, 2008.

[67] P. S. Gamito, D. G. Morais, J. G. Oliveira, R. Brito, P. J. Rosa, and M. G. De Matos, "Frequency is not enough: Patterns of use associated with risk of Internet addiction in Portuguese adolescents," Computers in Human Behavior, vol. 58, pp. 471$478,2016$.

[68] J. J. Gross, "Antecedent- and response-focused emotion regulation: Divergent consequences for experience, expression, and physiology.", Journal of Personality and Social Psychology, vol. 74, no. 1, pp. 224-237, 1998.

[69] L. R. N. Schreiber, J. E. Grant, and B. L. Odlaug, "Emotion regulation and impulsivity in young adults," Journal of Psychiatric Research, vol. 46, no. 5, pp. 651-658, 2012.

[70] M. M. Spada, B. Langston, A. V. Nikčević, and G. B. Moneta, "The role of metacognitions in problematic Internet use," Computers in Human Behavior, vol. 24, no. 5, pp. 2325-2335, 2008.

[71] P. Jeammet, "La violence à l'adolescence: une défense identitaire," Neuropsychiatrie de l'Enfance et de l'Adolescence, vol. 50, no. 6-7, pp. 434-441, 2002.

[72] T. Chung, "Adolescent substance use: symptoms and course," in Principles of Addiction: Comprehensive Addictive Behaviors and Disorders, P. E. Miller, Ed., vol. 1, pp. 97-106, Elsevier, San Diego, Calif, USA, 2013.

[73] L. Cerniglia, S. Cimino, G. Ballarotto et al., "Motor vehicle accidents and adolescents: an empirical study on their emotional and behavioral profiles, defense strategies and parental support," Transportation Research Part F: Traffic Psychology and Behaviour, vol. 35, pp. 28-36, 2015.

[74] S. Guarino and L. Vismara, "Mental state of attachment and reflective function in a group of antisocial adolescents," Psicologia Clinica dello Sviluppo, vol. 16, no. 3, pp. 579-598, 2012.

[75] B. T. Wymbs, C. A. McCarty, K. M. King et al., "Callousunemotional traits as unique prospective risk factors for substance use in early adolescent boys and girls," Journal of Abnormal Child Psychology, vol. 40, no. 7, pp. 1099-1110, 2012.

[76] D. Carlotta, R. F. Krueger, K. E. Markon et al., "Adaptive and maladaptive personality traits in high-risk gamblers," Journal of Personality Disorders, vol. 29, no. 3, pp. 378-392, 2015.

[77] M. R. Dadds, N. Gale, M. Godbee et al., "Expression and regulation of attachment-related emotions in children with conduct problems and callous-unemotional traits," Child Psychiatry \& Human Development, vol. 47, no. 4, pp. 647-656, 2016.
[78] D. C. Bennett and P. K. Kerig, "Investigating the construct of trauma-related acquired callousness among delinquent youth: differences in emotion processing," Journal of Traumatic Stress, vol. 27, no. 4, pp. 415-422, 2014.

[79] L. A. Schneider, D. L. King, and P. H. Delfabbro, "Family factors in adolescent problematic Internet gaming: a systematic review," Journal of Behavioral Addictions, vol. 6, no. 3, pp. 321-333, 2017.

[80] A. Besser and S. J. Blatt, "Identity consolidation and internalizing and externalizing problem behaviors in early adolescence," Psychoanalytic Psychology, vol. 24, no. 1, pp. 126-149, 2007.

[81] C. McKinney, R. Donnelly, and K. Renk, "Perceived parenting, positive and negative perceptions of parents, and late adolescent emotional adjustment," Child and Adolescent Mental Health, vol. 13, no. 2, pp. 66-73, 2008.

[82] R. Tambelli, S. Cimino, L. Cerniglia, and G. Ballarotto, "Early maternal relational traumatic experiences and psychopathological symptoms: a longitudinal study on mother-infant and father-infant interactions," Scientific Reports, vol. 5, Article ID 13984, 2015.

[83] J.-A. Lim, A. R. Gwak, S. M. Park et al., "Are adolescents with internet addiction prone to aggressive behavior? The mediating effect of clinical comorbidities on the predictability of aggression in adolescents with internet addiction," Cyberpsychology, Behavior, and Social Networking, vol. 18, no. 5, pp. 260-267, 2015.

[84] A. Tsitsika, E. Critselis, A. Louizou et al., "Determinants of internet addiction among adolescents: a case-control study," The Scientific World Journal, vol. 11, pp. 866-874, 2011.

[85] L. Milani, D. Osualdella, and P. Di Blasio, "Quality of interpersonal relationships and problematic internet use in adolescence," Cyberpsychology, Behavior, and Social Networking, vol. 12, no. 6, pp. 681-684, 2009.

[86] F. Laghi, B. H. Schneider, I. Vitoroulis et al., "Knowing when not to use the Internet: Shyness and adolescents' on-line and off-line interactions with friends," Computers in Human Behavior, vol. 29, no. 1, pp. 51-57, 2013.

[87] L. M. Cheung and W. S. Wong, "The effects of insomnia and internet addiction on depression in Hong Kong Chinese adolescents: An exploratory cross-sectional analysis," Journal of Sleep Research, vol. 20, no. 2, pp. 311-317, 2011.

[88] M. Di Nicola, V. R. Ferri, L. Moccia et al., "Gender differences and psychopathological features associated with addictive behaviors in adolescents," Frontiers in Psychiatry, vol. 8, article 256, 2017.

[89] The ESPAD Group, "Results from the European school survey project on alcohol and other drugs," ESPAD Report 2015, European Monitoring Centre for Drugs and Drug Addiction (EMCDDA), Lisbon, Portugal, 2016. 


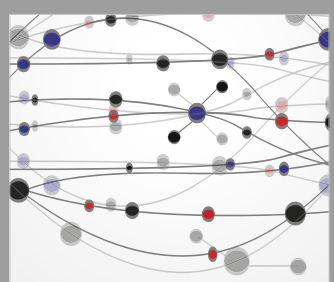

The Scientific World Journal
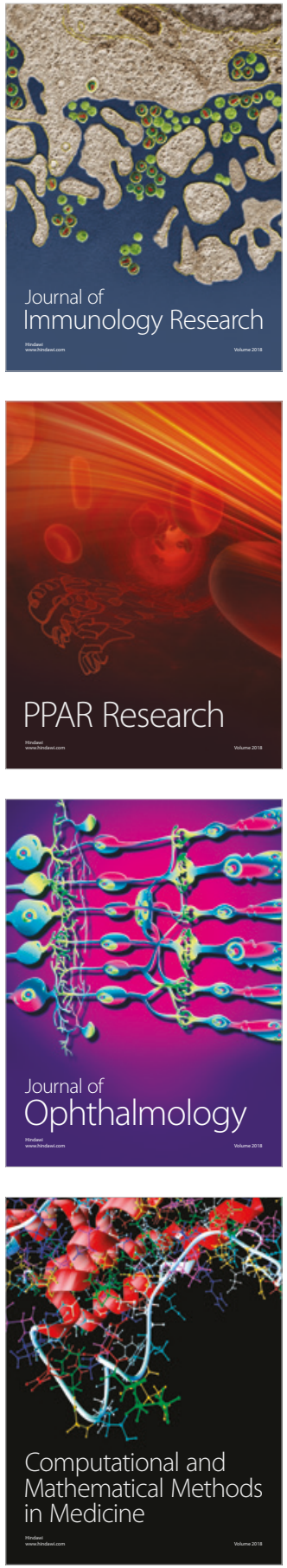

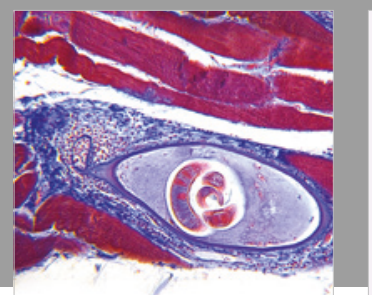

Gastroenterology Research and Practice

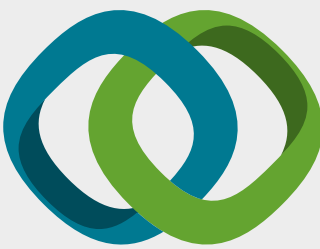

\section{Hindawi}

Submit your manuscripts at

www.hindawi.com
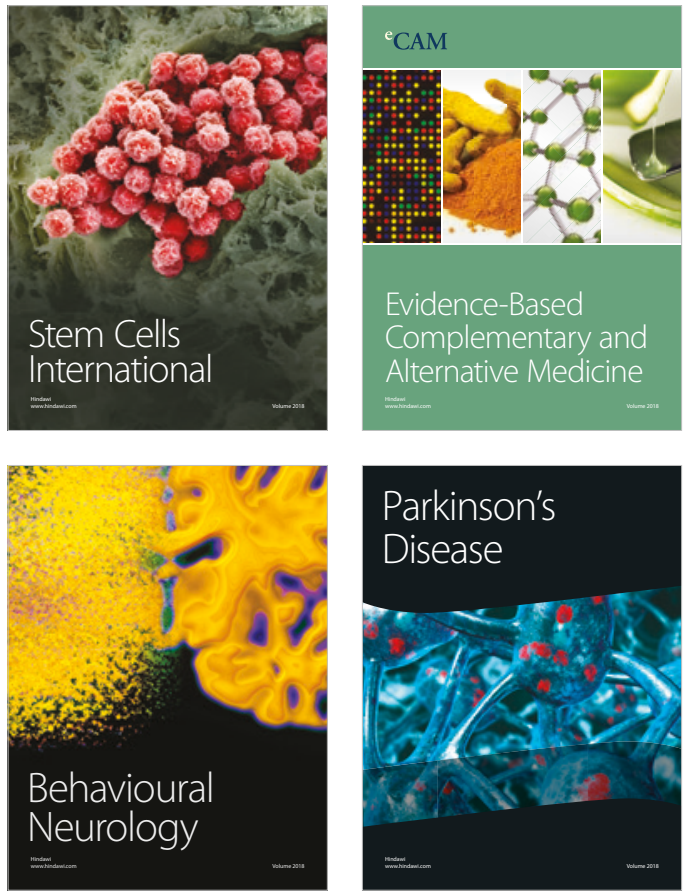

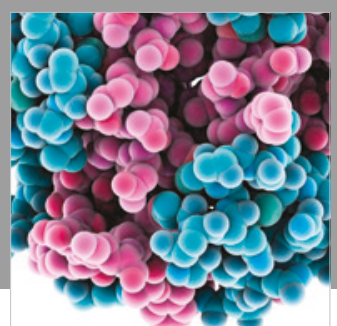

ournal of

Diabetes Research

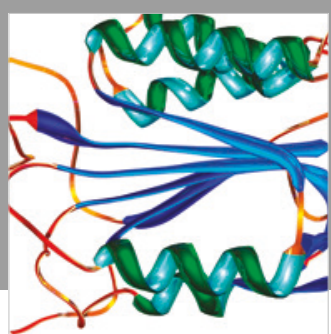

Disease Markers
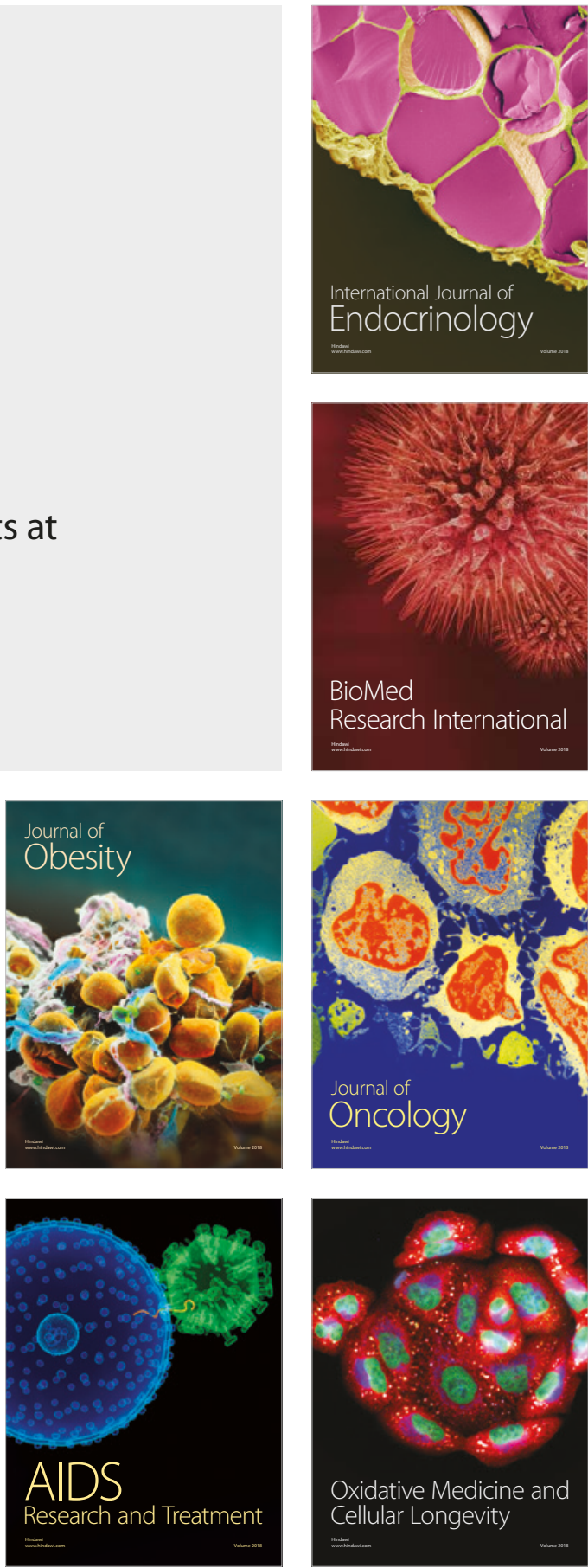